Check for updates

Cite this: RSC Adv., 2018, 8, 22924

\title{
Enhanced biohydrogen production from nutrient- free anaerobic fermentation medium with edible fungal pretreated rice straw
}

\author{
Tao Sheng, (D) ab Lei Zhao, (D) *ad Lingfang Gao, ${ }^{c}$ Wenzong Liu, ${ }^{\text {*c }}$ Guofeng Wu, ${ }^{\text {e }}$ \\ Jieting $\mathrm{Wu}^{f}$ and Aijie Wang (D)
}

An edible fungal pretreatment of rice straw was proposed for enhanced hydrogen production while reducing the chemical cost for traditional biological hydrogen production from lignocellulose. In this research, rice straw was pretreated by edible fungus Gymnopus contrarius $\mathrm{J} 2$ at room temperature under static conditions for $15 \mathrm{~d}$ at first. The highest hydrogen yield of $5.71 \mathrm{mmol} \mathrm{g}{ }^{-1}$-pretreated rice straw was obtained, $74 \%$ higher than the counterpart without pretreatment. Chemical composition analysis demonstrated that lignin removal was up to $22.4 \%$ with a little cellulose and hemicellulose loss of $13.3 \%$ and $17.1 \%$, respectively, which is in favor of hydrogen production. Additionally, microscopic structure observation combined with FT-IR and XRD analysis illustrated the structural disruption of pretreated rice straw, and the crystalline index of rice straw can be decreased by $46.2 \%$ after pretreatment, which might account for the hydrogen production enhancement. The results also indicated that the hydrogen yield from pretreated rice straw was not affected without the addition of yeast extract and vitamins to the culture medium, which is substantial evidence that edible fungal pretreated rice straw could provide prerequisite nutrients for hydrogen-producing bacteria. Overall, edible fungal pretreatment has great potential under the mild conditions for high hydrogen yields and thus leads to a new direction to realize a highly efficient and economically competitive biological hydrogen production process from lignocellulosic biomass.

Received 19th April 2018

Accepted 19th June 2018

DOI: $10.1039 / \mathrm{c} 8 \mathrm{ra03361g}$

rsc.li/rsc-advances biological hydrogen (bio- $\mathrm{H}_{2}$ ) production from lignocellulosic biomass has been widely regarded as one of the most promising approaches due to its environmentally friendly and sustainable process. In China, agricultural wastes make-up the majority of lignocellulosic biomass. Take rice straw as an example, the annual yield is over 230 million tons, ${ }^{3}$ however, most of which is used for combustion directly, leading to severe environmental pollution and enormous resource waste. If rice straw can be used for $\mathrm{H}_{2}$ production reasonably, additional value would be gained for both environmental and economic benefits. ${ }^{4}$

Given the crystallinity and heterogeneity of lignocellulose, direct bioconversion of rice straw to $\mathrm{H}_{2}$ has significantly been hindered. ${ }^{5}$ Hence, selecting an appropriate pretreatment method to disrupt the crystalline structure of rice straw, and increase the accessibility of cellulose and hemicellulose embedded in lignin matrix for $\mathrm{H}_{2}$ producing bacteria is essential. ${ }^{6}$ Conventional lignocellulose pretreatment mainly includes physical, chemical, and combined physicochemical methods (e.g., grinding, ultrasonic, microwave, alkali, acid, stream explosion, organosolv, and ionic liquid). ${ }^{7}$ However, most of these approaches are cost-intensive due to high energy and/or chemical requirements, ${ }^{8}$ the severe pretreatment conditions induced by acid, alkaline, and high temperature also produce various inhibitory byproducts such as furfural and 
hydroxymethyl furfural (HMF) that would repress the subsequent fermentation process. ${ }^{9}$ Thus, downstream detoxification is needed, which will unquestionable increase the complexity and cost of the whole fermentation process. In addition, the dumped excessive chemical liquids will lead to severe negative environmental consequences.

Biological pretreatment has been emerging as the most promising methods in recent years, ${ }^{\mathbf{1 0}}$ it offers advantages such as low investment cost, little energy and chemicals requirement, and mild pretreatment condition when compared with physicochemical pretreatment methods. What's more, no inhibitors that are affecting the following hydrolysis and fermentation processes will be generated, ${ }^{\mathbf{1 1}}$ thus the procedure related to detoxification can be avoided. The main drawback to the development of biological methods is the low fermentation rate obtained compared to other technologies. To move forward to a more competitive biological lignocellulose pretreatment process, and improve $\mathrm{H}_{2}$ yields, there is a need to keep on studying more fungi for their ability to delignify lignocellulose efficiently. Recent research results showed that during vegetative growth period, the lignin degradation ratio of edible fungi was higher than the cellulose and hemicellulose, ${ }^{\mathbf{1 2}}$ thus suggesting a great potential to apply on pretreatment of lignocellulose. In addition to the common advantages of inedible fungal pretreatment, edible fungal pretreatment owns some unique features. Firstly, edible fungi processed feedstock can be used for biofuel production directly. ${ }^{13}$ Besides, edible fungi contained lysine, arginine, and threonine in high concentration, which is an obvious indicator that edible fungi may not only pretreat lignocellulose on purpose, but also owns the potential to provide nutrients for bioenergy producers. ${ }^{\mathbf{1 3 , 1 4}}$ Although some studies showed the mushroom (common edible fungi) waste could be used as the feedstock of bio- $\mathrm{H}_{2},{ }^{15,16}$ till now, no research is available on $\mathrm{H}_{2}$ production from edible fungal pretreated lignocellulose.

Therefore, this study was carried out to investigate if edible fungal pretreatment could improve $\mathrm{H}_{2}$ yield from rice straw without nutrient addition. The biodelignification characteristics of edible fungus Gymnopus contrarius $\mathrm{J} 2$ pretreated rice straw were described first. After that the pretreated rice straw was subjected to $\mathrm{H}_{2}$ production by Thermoanaerobacterium thermosaccharolyticum DD32 (ref. 17) directly to evaluate the enhancement efficiency of edible fungal pretreatment. At last, the nitrogen source and vitamin were removed from the $\mathrm{H}_{2}$ producing culture medium to confirm if edible fungal pretreated rice straw could provide sufficient nutrient to support bacterial growth and $\mathrm{H}_{2}$ production. This is the first study to employ edible fungal pretreatment of rice straw for enhanced $\mathrm{H}_{2}$ production from nutrient-free anaerobic fermentation medium.

\section{Materials and methods}

\subsection{Preparation of raw feedstock}

The rice straw used in this research was collected from Shuangyashan farm, Heilongjiang Province, China. The air- dried feedstock was milled to pass through 40-mesh screen at first, then dried under $40^{\circ} \mathrm{C}$ until constant weight was obtained.

\subsection{Edible fungal pretreatment of rice straw}

The edible fungus Gymnopus contrarius $\mathrm{J} 2$ was provided by College of Life Science (Heilongjiang University, Heilongjiang Province, China) and maintained on potato dextrose agar (PDA) plates at $4{ }^{\circ} \mathrm{C}$. Sterilized $250 \mathrm{~mL}$ Erlenmeyer flask containing $100 \mathrm{~mL}$ basic medium were prepared to activate the fungus as described by Swatzell et al. (1996). ${ }^{18}$ Five pieces of agar medium (about $0.9 \mathrm{~cm}$ in diameter) with fungus mycelium was inoculated into each Erlenmeyer flask, and then cultured in an incubator at $28{ }^{\circ} \mathrm{C}$ under static conditions for 7 days. Then the edible fungal pretreatment was carried out with grown liquid culture as inoculum. $3 \mathrm{~g}$ preserved rice straw samples were added to $250 \mathrm{~mL}$ Erlenmeyer flasks, distilled water containing $4 \mathrm{mg} \mathrm{L}{ }^{-1} \mathrm{NaNO}_{3}, 10 \mathrm{mg} \mathrm{L}{ }^{-1} \mathrm{KCl}, 14 \mathrm{mg} \mathrm{L}{ }^{-1} \mathrm{MgSO}_{4} \cdot 7 \mathrm{H}_{2} \mathrm{O}$, $0.14 \mathrm{mg} \mathrm{L}^{-1} \mathrm{FeSO}_{4} \cdot 7 \mathrm{H}_{2} \mathrm{O}$, and $40 \mathrm{mg} \mathrm{L}{ }^{-1} \mathrm{KH}_{2} \mathrm{PO}_{4}$ was adjusted to obtain a moisture content of $65 \% .{ }^{19,20}$ After the autoclaved Erlenmeyer flasks containing wet rice straw were cooled to room temperature, each flask was inoculated with $2 \mathrm{~mL}$ of homogeneous liquid culture prepared before. After that, the flasks were sealed with a sterile sealing membrane to allow air exchange. Edible fungal pretreatment was conducted at room temperature $\left(25{ }^{\circ} \mathrm{C}\right)$ under static condition for 21 days. Erlenmeyer flasks without fungus inoculation were conducted as control. Samples were taken every third day for further analysis. All tests were performed in triplicate. Solid fractions after pretreatment were dried at $40{ }^{\circ} \mathrm{C}$ for $24 \mathrm{~h}$ and then kept at $4{ }^{\circ} \mathrm{C}$ for further chemical analysis and $\mathrm{H}_{2}$ production.

\subsection{Bio- $\mathrm{H}_{2}$ potential tests}

Raw and pretreated rice straw samples were fermented by strain T. thermosaccharolyticum DD32, isolated by Sheng et al., (2015) ${ }^{17}$ that could use lignocellulose for $\mathrm{H}_{2}$ production under anaerobic condition directly. Fermentations were conducted in $100 \mathrm{~mL}$ serum bottles with $50 \mathrm{~mL}$ culture medium containing: $3.0 \mathrm{~g} \mathrm{~L}^{-1}$ $\mathrm{K}_{2} \mathrm{HPO}_{4} ; 1.5 \mathrm{~g} \mathrm{~L}^{-1} \mathrm{KH}_{2} \mathrm{PO}_{4} ; 1.0 \mathrm{~g} \mathrm{~L}^{-1} \mathrm{NaCl} ; 0.2 \mathrm{~g} \mathrm{~L}^{-1} \mathrm{KCl} ; 0.2 \mathrm{~g}$ $\mathrm{L}^{-1} \mathrm{MgCl}_{2} ; 1.0 \mathrm{~g} \mathrm{~L}^{-1} \mathrm{NH}_{4} \mathrm{Cl} ; 1.5 \mathrm{~g} \mathrm{~L}^{-1}$ yeast extract; $0.5 \mathrm{~g} \mathrm{~L}^{-1}$ cysteine- $\mathrm{HCl} ; 1.0 \mathrm{~mL} \mathrm{~L}^{-1}$ vitamin solution; $1.0 \mathrm{~mL} \mathrm{~L}^{-1}$ trace element solution; and $5.0 \mathrm{~g} \mathrm{~L}^{-1}$ rice straw with or without pretreatment unless otherwise stated as carbon source, vitamin solution and trace element solution were prepared as described by Wolin et al. (1963). ${ }^{21}$ All fermentation tests were carried out at $55{ }^{\circ} \mathrm{C}$ with an initial $\mathrm{pH}$ of 7.5 , in an orbital incubator shaker with a rotation speed of $150 \mathrm{rpm}$ for 96 hours. Samples were taken every $6 \mathrm{~h}$ to determine gas production, biomass concentration, substrate degradation, and liquid end products. All bio$\mathrm{H}_{2}$ production tests were performed in triplicate.

\subsection{Analytical methods}

Automatic cellulose analyzer (ANKOM A200i, USA) was used to detect the rice straw composition before and after edible fungal pretreatment in accordance with the manufacturer's instructions. ${ }^{17}$ To observe the microstructural changes of rice straw caused by edible fungal pretreatment, the rice straw samples 
were rinsed with water at first, then the dried samples were prepared by mounting on stubs and sputter-coated with gold for scanning electron microscopic (SEM, JEOL JSM-840 SEM 1-5 $\mathrm{kV}$ ) analysis. Fourier transform infrared spectroscopy (FT-IR) spectra of rice straw samples were analyzed on a Magna-IR 750 (Nicolet Instrument Co., USA) FT-IR Microscope. Each spectrum was recorded in the range between 4000 and $400 \mathrm{~cm}^{-1}$, with the background pure potassium bromide spectrum subtracted from the sample. The crystallinity index (CrI) of rice straw was determined by X-ray diffraction (XRD) using the deconvolution method. ${ }^{22}$ The gas composition and volatile fatty acids concentration during $\mathrm{H}_{2}$ fermentation was determined by GC (4800, Agilent Technologies, USA), with detected conditions as established by Wang et al. (2011). ${ }^{23}$ High-performance liquid chromatography (HPLC, LC-10A, Shimadzu Corporation, Kyoto, Japan) equipped with an Aminex HPX-87 P column (Bio-Rad, Hercules, CA) at $80{ }^{\circ} \mathrm{C}$, using $0.02 \mathrm{~mol} \mathrm{H}_{2} \mathrm{SO}_{4}$ as eluent at a flow rate of $0.4 \mathrm{~mL} \mathrm{~min}^{-1}$ was employed to measure the potential reducing sugars exist in the supernatant of culture broth. $^{24}$ Biomass concentration of $T$. thermosaccharolyticum DD32 was estimated using the Bradford method ${ }^{25}$ that has been described by Wiegel et al. (2008). ${ }^{26}$ Activities of cellulase and hemicellulase secreted by $\mathrm{H}_{2}$-producing bacteria $T$. thermosaccharolyticum DD32 were measured by the method established by Wood and Bhat (1988). ${ }^{27}$

Analysis of variance (ANOVA) and a Tukey's post hoc test was conducted to compute significant differences among $\mathrm{H}_{2}$ production from different pretreatment time. A $P$ value of less than 0.05 was considered statistically significant.

\section{Results and discussion}

\subsection{Edible fungal pretreatment of rice straw}

3.1.1 Chemical composition of raw and pretreated rice straw. To evaluate the lignocellulose degradation efficiency of fungus Gymnopus contrarius J2, chemical composition of rice straw as a function of pretreatment time was analyzed at first and the results were shown in Fig. 1. The raw rice straw used in this study contained $50.4 \%$ cellulose, $28.7 \%$ hemicellulose, and $19.9 \%$ lignin. Shortly after inoculating $G$. contrarius $\mathrm{J} 2$ to the pretreatment medium, rice straw began to be degraded. It can be obtained from

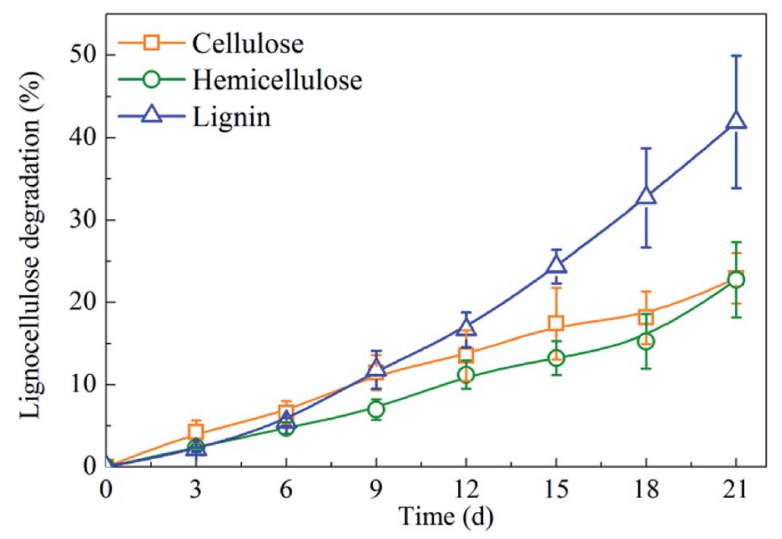

Fig. 1 Rice straw degradation profile after edible fungal pretreatment.
Fig. 1 that the cellulose and hemicellulose degradation efficiency was faster than lignin at the beginning. However, 9 days later, an interesting phenomenon was observed that lignin degradation rate began to increase, and the value was even higher than cellulose and hemicellulose. When the processing time extended from 15 d to $18 \mathrm{~d}$, lignin degradation ratio was apparently increased $(22.4 \%$ to $31.7 \%$ ), at the same time, the cellulose and the hemicellulose degradation ratio were slightly increased $1.8 \%$ (13.3\% to $15.1 \%)$ and $1.1 \%(17.1 \%$ to $18.2 \%)$ respectively. After $21 \mathrm{~d}$ pretreatment, $41.9 \%$ lignin was removed, accompanied with $22.9 \%$ cellulose and $22.7 \%$ hemicellulose loss. To prevent further cellulose and hemicellulose loss, and taking into account the whole pretreatment efficiency, the edible fungal pretreatment was carried out for 21 $\mathrm{d}$ in the following experiments. During conventional physicochemical pretreatment processes, abundant cellulose and hemicellulose loss is inevitable. ${ }^{28}$ Although biological pretreatment is a good method for cellulose and hemicellulose preservation, biological degradation characteristics of lignocellulose varies with different fungi adopted. ${ }^{29-31}$ For example, Phanerochaete chrysosporium could degrade more cellulose (55.67\%) than lignin (18.89\%) within 20 days' wheat straw pretreatment, ${ }^{32}$ Song et al. (2004) employed Pleurotus cetrinopileatus to pretreat corn straw, the same amount of holocellulose (5.4\%) and lignin (5.6\%) was removed. When using Pholiota nameko for straw pretreatment, cellulose removal ratio (17.3\%) was in advance of lignin $(14.1 \%){ }^{33}$ Actually, a higher level of cellulose and hemicellulose content would be favourable for microorganism that could ferment lignocellulosic biomass for bioenergy production. Compared with the reports regarding biological pretreatment by far, the lignin removal and cellulose and hemicellulose reservation yield obtained in this research is the highest. This result primarily indicates that edible fungus $G$. contrarius J2 owns high potential for application on lignocellulose pretreatment.

3.1.2 Biochemical and structural features of raw and pretreated rice straw. SEM was employed to give an insight into the structural modifications of rice straw with different pretreatment time. As shown in Fig. 2, in accordance with the chemical composition of raw and pretreated rice straw, the untreated rice straw showed compact and smooth flat surface, and little corrosion was found on rice straw pretreated with $9 \mathrm{~d}$ (Fig. 2A and $\mathrm{B}$ ).

However, after $12 \mathrm{~d}$ pretreatment, the surface structure of the pretreated rice straw became rugged and less compact, even some minor erosion was generated (Fig. 2C). When further extend the pretreatment time to $15 \mathrm{~d}$, the initial connected structure became loose, and more erosion troughs and cracks can be observed on the surface of pretreated rice straw (Fig. 2D). The high lignin, cellulose and hemicellulose ratio from 15 days to 18 days leads to the depolymerization of rice straw structure. After $21 \mathrm{~d}$ pretreatment, the structure of the rice straw was severely destructed, and plenty of cracks and large holes can be found (Fig. 2F). The SEM analysis could further demonstrate from the point of surface morphology that the edible fungal pretreatment could give rise to the serious structural destruction of rice straw that is suitable for further fermentation. FT-IR was also applied as an analytical tool to determine the chemical structural changes of rice straw under different pretreatment 

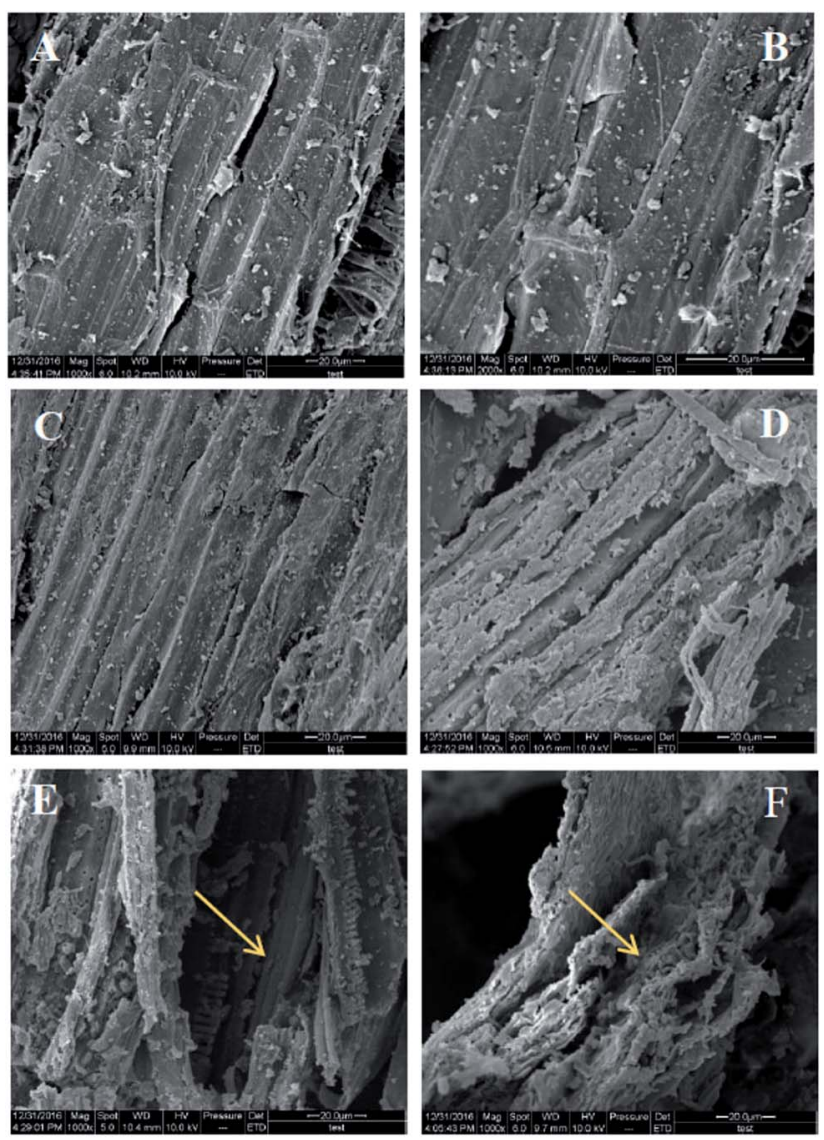

Fig. 2 Scanning electron micrographs (SEMs) of rice straw under different pretreatment duration. (A) $0 \mathrm{~d}$, (B) $9 \mathrm{~d}$, (C) $12 \mathrm{~d}$, (D) $15 \mathrm{~d}$, (E) 18 d, (F) $21 \mathrm{~d}$.

time. The FT-IR spectra of samples were shown in Fig. 3, the functional groups change of pretreated rice straw were particularly reflected between the absorbance spectra $400 \mathrm{~cm}^{-1}$ and $1800 \mathrm{~cm}^{-1}$. The band at $1728 \mathrm{~cm}^{-1}$ (related to the uronic acid ester bonds formed between the carboxylic acid group in hemicellulose and the phenolic hydroxyl group in $\operatorname{lignin}^{34}$ ), $1603 \mathrm{~cm}^{-1}$ and $1512 \mathrm{~cm}^{-1}$ (assigned to aromatic skeletal vibrations in lignin ${ }^{35}$ ), $1464 \mathrm{~cm}^{-1}$ (associated with $\mathrm{C}-\mathrm{H}$ deformations in lignin), $1416 \mathrm{~cm}^{-1}$ (possibly associated with

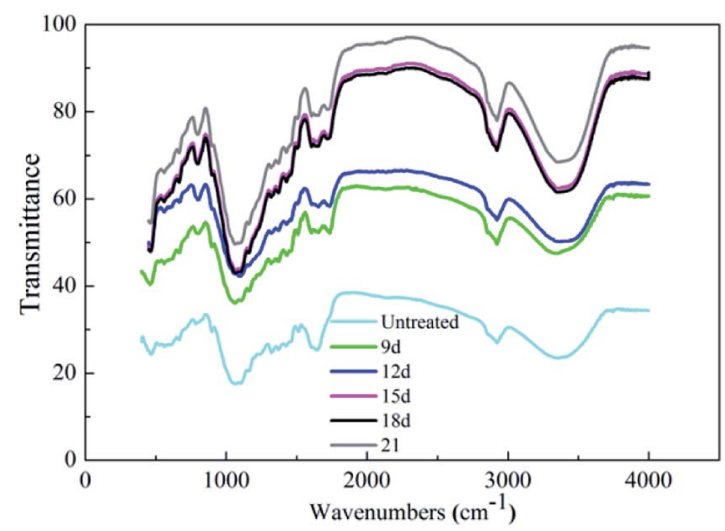

Fig. 3 FT-IR spectra of raw and pretreated rice straw samples. nonesterified uronic acid or phenolic rings $\left.{ }^{36}\right), 1244 \mathrm{~cm}^{-1}$ (assigned to $\beta$-ether bonds in lignin and between lignin and carbohydrates ${ }^{35}$ ), and $835 \mathrm{~cm}^{-1}$ (possibly belonging to a $\mathrm{C}-\mathrm{H}$ out of plane vibration in lignin $)^{37}$ all diminished in the FT-IR spectrum of Gymnopus contrarius J2 pretreated rice straw. Such results further confirm the chemical components and SEM microstructural analysis.

3.1.3 The crystallinity of raw and pretreated rice straw. The main purpose of pretreatment is not only to remove lignin, but also to break the inter- and intra-chain hydrogen bonding of cellulose fibrils and destruct the cellulose crystalline structure in rice straw, ${ }^{38}$ thus making the feedstock more accessible to a broad range of microorganisms. In order to investigate the crystallinity changes of rice straw under different pretreatment time, X-ray diffraction (XRD) was performed and the XRD patterns of the raw and pretreated rice straw were shown in Fig. 4. It can be obtained from the results that the crystalline index of raw rice straw was 0.39 . After pretreated by G. contrarius $\mathrm{J} 2$ for $9 \mathrm{~d}$, the crystalline index was slightly declined to 0.36 , which coincide with the chemical composition changes of rice straw. After $15 \mathrm{~d}$ pretreatment, the crystalline index of rice straw dramatically declined to $0.21,46.2 \%$ crystallinity reduction of rice straw was achieved. When further increase the operational time, the crystalline index of pretreated rice straw was stepwise decreased from 0.20 to 0.17 , which indicated that a maximum of $56.4 \%$ crystallinity reduction of rice straw could be achieved after $21 \mathrm{~d}$ pretreatment. Crystalline index is an important indicator to evaluate the efficiency of the pretreatments, and the XRD method has been adopted by many researchers. Ma et al. $(2015)^{39}$ pretreated corncob with alkaline potassium permanganate, the reduction of crystalline index after pretreatment was only $2.53 \%$. When microwave-assisted calcium chloride was adopted for corn stover pretreatment by Li et al., (2013), ${ }^{\mathbf{4 0}}$ the crystalline index was decreased by only $13.91 \% .{ }^{40}$ From these research results, it can be obtained that $G$. contrarius $\mathrm{J} 2$ pretreatment is a promising method to remove lignin, preserve holocellulose, and decrease the crystalline of rice straw. The pretreatment efficiency can even compare to physicochemical pretreatment, thus suggesting a promising application prospect.

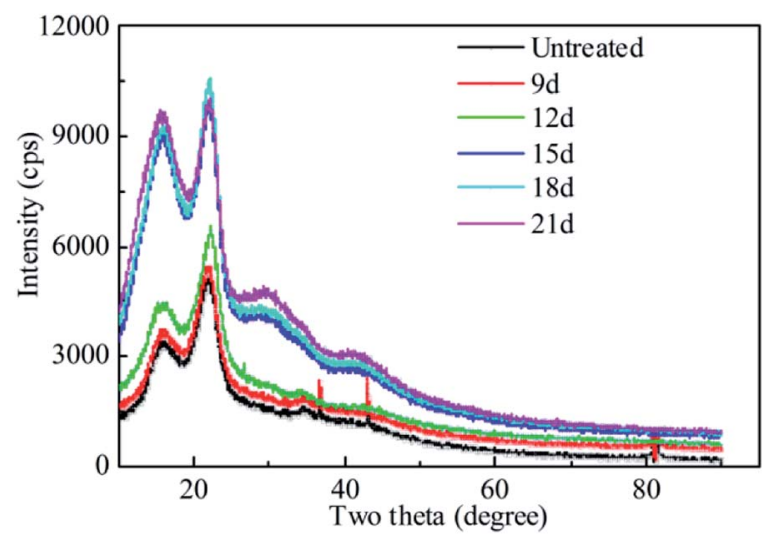

Fig. 4 X-ray diffraction spectra of raw and pretreated rice straw samples. 


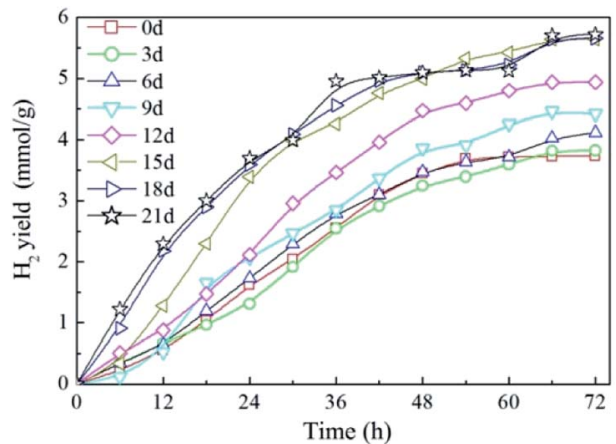

Fig. 5 Profile of $\mathrm{H}_{2}$ production from edible fungal pretreated rice straw.

\subsection{Edible fungal pretreatment for enhanced $\mathrm{H}_{2}$ production}

3.2.1 $\mathrm{H}_{2}$ production profile from edible fungal pretreated rice straw. $\mathrm{H}_{2}$ production profile from rice straw pretreated by edible fungus $G$. contrarius $\mathrm{J} 2$ was shown in Fig. 5 . It can be obviously found that $\mathrm{H}_{2}$ production yield was promoted by increasing the pretreatment time within $15 \mathrm{~d}$, the maximum $\mathrm{H}_{2}$ yield of $5.71 \mathrm{mmol} \mathrm{g}^{-1}$ was obtained from $15 \mathrm{~d}$ pretreated rice straw, $74 \%$ higher than that without pretreatment. When rice straw with longer pretreatment time was used as substrate, the $\mathrm{H}_{2}$ production yield kept constant $\left(5.65 \mathrm{mmol} \mathrm{g}^{-1}\right.$ and $5.71 \mathrm{mmol} \mathrm{g}^{-1}$ for $18 \mathrm{~d}$ and $21 \mathrm{~d}$ respectively). In theory, the more time spend on pretreatment, the more $\mathrm{H}_{2}$ yields. However, in this research, as the pretreatment time longer than $15 \mathrm{~d}$, lignin removal was accompanied with less cellulose and hemicellulose preservation. Since the substrate available for $\mathrm{H}_{2}$ producing bacteria is limited, the $\mathrm{H}_{2}$ production yield from rice straw would not be increased anymore after $15 \mathrm{~d}$ pretreatment, similar results have also been verified by Zhao et al. (2014). ${ }^{5}$

3.2.2 Comparison of $\mathrm{H}_{2}$ production from edible fungal pretreated rice straw with and without nutrient addition. As mentioned at the beginning of this paper, edible fungi could not only depose the structure of lignocellulosic feedstock, but also improve the nutritive value of lignocellulose. ${ }^{41}$ The edible fungi themselves were good resources of digestible proteins, $\beta$ glucans, and B-vitamins ${ }^{42}$ that were necessary for microorganism growth. Therefore, if edible fungal pretreated rice straw was subjected to $\mathrm{H}_{2}$ fermentation directly, it is feasible to reduce the addition of essential nutrient elements to $\mathrm{H}_{2}$ producing medium, and thus further reduce the $\mathrm{H}_{2}$ production cost. In this research, $\mathrm{H}_{2}$ production potential tests were carried out from $15 \mathrm{~d}$ pretreated rice straw, the organic nitrogen source yeast extract (YE), vitamin solution, and a combination of both were omitted from the $\mathrm{H}_{2}$ fermentation hemicellulose preservation, $\mathrm{H}_{2}$ yield, and additional nutrients provided, edible fungal pretreatment would be suggested as a promising pretreatment method for enhancing direct $\mathrm{H}_{2}$ production from lignocellulose. The results presented here demonstrate a new biological conversion of lignocellulosic culture separately. Rice straw without pretreatment was used as control. As shown in Fig. 6a, when raw rice straw was used as substrate, the maximum $\mathrm{H}_{2}$ yield of $3.72 \mathrm{mmol} \mathrm{g}^{-1}$ was obtained from the culture contained both YE and vitamin. This value was much higher than the medium without YE (2.51 $\left.\mathrm{mmol} \mathrm{g}^{-1}\right)$ and vitamin $\left(3.24 \mathrm{mmol} \mathrm{g}^{-1}\right)$ separately, and a mixture of both $\left(2.24 \mathrm{mmol} \mathrm{g}^{-1}\right)$. When the pretreated rice straw was used as substrate, the $\mathrm{H}_{2}$ yield obtained from the medium without addition of YE and vitamin was $5.21 \mathrm{mmol} \mathrm{g}^{-1}$ (Fig. 6b), this value was not significant different $(P$-value $>0.05)$ from the medium contained both $\mathrm{YE}$ and vitamin $\left(5.63 \mathrm{mmol} \mathrm{\textrm {g } ^ { - 1 }}\right)$. What's more, the maximum $\mathrm{H}_{2}$ production yield obtained in this research was comparable to relevant studies through physicochemical pretreatments and even higher than the biological pretreatments (as shown in Table 1). The cellulose and hemicellulose degradation ratios of rice straw were further investigate to give an insight into the phenomenon. As shown in Fig. $6 \mathrm{c}$ and d. In accordance with $\mathrm{H}_{2}$ production profile, when pretreated rice straw was used as substrate, the cellulose and hemicellulose degradation ratios were similar to each other. However, the value differed when raw rice straw was used as substrate, as YE, vitamin, or a mixture of both was removed from culture medium, the holocellulose degradation ratio declined obviously. The activities of cellulase (endo-glucanase and exo-glucanase) and hemicellulase (xylanase and $\beta$-xylosidase) were also measured and the results listed in Table 2 showed that although YE, vitamin, and a mixture of both were removed from the medium respectively, the cellulase and hemicellulase activities were almost not affected. While the cellulase and hemicellulase activities with raw rice straw as substrate presented a different performance. When YE, vitamin, or a mixture of both was removed from the medium respectively, the maximum activities of $\beta$-D-glucanohydrolase, endoglucanase, exo-glucanase, xylanase, and $\beta$-xylosidase were 2.04.5 times lower than that contained both YE and vitamin. Although $T$. thermosaccharolyticum DD32 could be able to use ammonia as nitrogen source, the cellulase and hemicellulase activities can be only promoted by the organic nitrogen source. ${ }^{43}$ The results obtained above demonstrated that edible fungal pretreatment is an efficient pretreatment method for enhanced

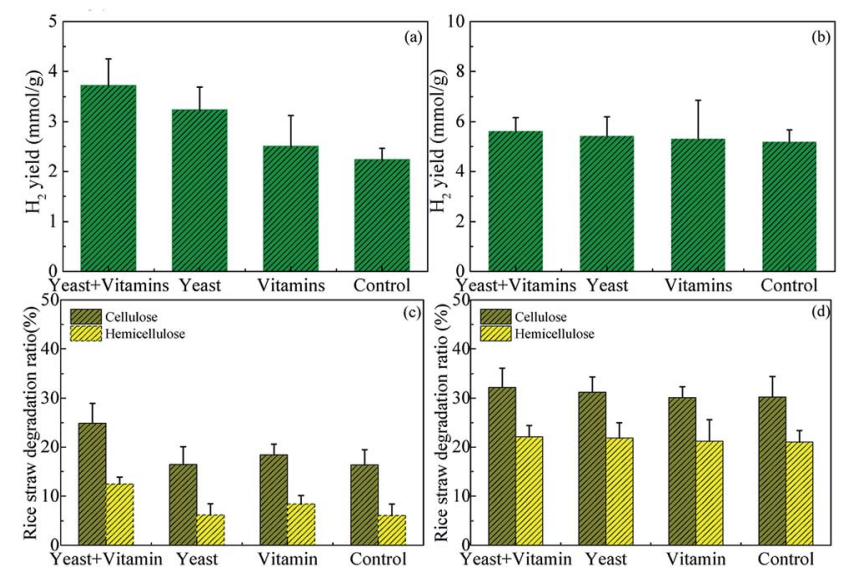

Fig. $6 \mathrm{H}_{2}$ production from edible fungal pretreated rice straw with nutrient deletion. (a) $\mathrm{H}_{2}$ production from raw rice straw with nutrient deletion; (b) $\mathrm{H}_{2}$ production from edible fungal pretreated rice straw with nutrient deletion; (c) Substrate degradation of raw rice straw with nutrient deletion; (d) substrate degradation of edible fungal pretreated rice straw with nutrient deletion. 
Table 1 Comparison of $\mathrm{H}_{2}$ yields with other relevant works

\begin{tabular}{|c|c|c|c|c|c|}
\hline Microorganism & Temperature $\left({ }^{\circ} \mathrm{C}\right)$ & Substrate & Pretreatment method & $\mathrm{H}_{2}$ yield $\left(\mathrm{mL} \mathrm{g}^{-1}\right)$ & Ref. \\
\hline $\begin{array}{l}\text { Cow manure and a } \\
\text { sediment }\end{array}$ & 35 & Wheat straw & Ozone pretreatment for $45 \mathrm{~min}$ & 174.7 & 44 \\
\hline $\begin{array}{l}\text { Sewage sludge from a } \\
\text { local winery }\end{array}$ & 55 & $\begin{array}{l}\text { Mixed cornstalk } \\
\text { (treated/raw }=1 / 5)\end{array}$ & Fungal-pretreatment, & 48.7 & 46 \\
\hline T. thermosaccharolyticum & 60 & Cornstalk & Fungal-pretreatment, & 80.3 & 8 \\
\hline $\begin{array}{l}\text { T. thermosaccharolyticum } \\
\text { DD32 }\end{array}$ & 55 & Rice straw & Fungal-pretreatment & 126.1 & This study \\
\hline $\begin{array}{l}\text { T. thermosaccharolyticum } \\
\text { DD32 }\end{array}$ & 55 & Rice straw & Unpretreated & 68.09 & This study \\
\hline
\end{tabular}

Table 2 The cellulase/hemicellulase activities during $\mathrm{H}_{2}$ production from rice straw with and without nutrient addition

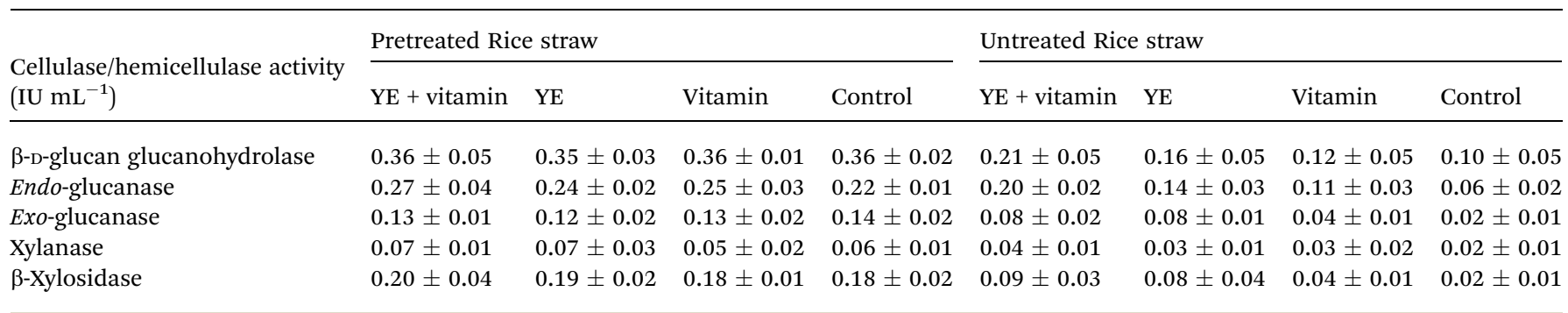

$\mathrm{H}_{2}$ production, and could provide sufficient nitrogen source and vitamins to support efficient lignocellulose hydrolysis by cellulase and hemicellulase. Overall, from the aspects of lignin removal, crystalline reduction, cellulose and biomass to $\mathrm{H}_{2}$ process which is more economically feasible and energy efficient.

\section{Conclusion}

This study demonstrated $\mathrm{H}_{2}$ production from rice straw can be greatly improved by employing edible fungal pretreatment. Rice straw pretreated with $G$. contrarius J2 for $15 \mathrm{~d}$ showed $22.4 \%$ lignin removal and $46.2 \%$ crystalline reduction with less cellulose and hemicellulose loss. Afterwards, the pretreated rice straw was subjected to $\mathrm{H}_{2}$ production by $T$. thermosaccharolyticum DD32 directly, high $\mathrm{H}_{2}$ yield of $5.21 \mathrm{mmol} \mathrm{g}^{-1}$ was obtained under the condition with or without nutrient addition. Overall, edible fungal pretreatment could be an economically and technically feasible approach for enhancing biological lignocellulosic biomass conversion to $\mathrm{H}_{2}$.

\section{Conflicts of interest}

There are no conflicts to declare.

\section{Acknowledgements}

This research was supported by the National Science Foundation for Distinguished Young Scholars (Grant No. 51225802). Lei Zhao acknowledges the Open Project of State Key Laboratory of Urban Water Resource and Environment, Harbin Institute of Technology (No. ES201810-01), the Fundamental Research Funds for the Central Universities (Grant No. HIT. NSRIF. 201859), China, and the UQ Fellowship (2016000091), UQ Early Career Research Grant (2017003152) from the University of Queensland, Australia.

\section{References}

1 M. Calusinska, C. Hamilton, P. Monsieurs, G. Mathy, N. Leys, F. Franck, B. Joris, P. Thonart, S. Hiligsmann and A. Wilmotte, Biotechnol. Biofuels, 2015, 8, 27.

2 B. F. Liu, G. J. Xie, R. Q. Wang, D. F. Xing, J. Ding, X. Zhou, H. Y. Ren, C. Ma and N. Q. Ren, Biotechnol. Biofuels, 2015, 8, 8.

3 Y. He, Y. Pang, Y. Liu, X. Li and K. Wang, Energy Fuels, 2008, 22, 2775-2781.

4 M. Kim, Y. Yang, M. S. Morikawa-Sakura, Q. Wang, M. V. Lee, D. Y. Lee, C. Feng, Y. Zhou and Z. Zhang, Int. J. Hydrogen Energy, 2012, 37, 3142-3149.

5 L. Zhao, G. L. Cao, A. J. Wang, H. Y. Ren, K. Zhang and N. Q. Ren, Biotechnol. Biofuels, 2014, 7, 178.

6 W. Seunggon, C. Eunjin, L. Daeseok, L. Soojung, L. Youngju and B. Hyeunjong, Biotechnol. Biofuels, 2015, 8, 228.

7 T. Sheng, L. Zhao, W. Z. Liu, L. Gao and A. J. Wang, RSC Adv., 2017, 7, 32076-32086.

8 L. Zhao, G.-L. Cao, A.-J. Wang, H.-Y. Ren, D. Dong, Z.-N. Liu, X.-Y. Guan, C.-J. Xu and N.-Q. Ren, Bioresour. Technol., 2012, 114, 365-369. 
9 E. Palmqvist and B. Hahn-Hägerdal, Bioresour. Technol., 2000, 74, 17-24.

10 Z. Jian, Z. Zhu, X. Wang, W. Nan, W. Wei and B. Jie, Biotechnol. Biofuels, 2010, 3, 26.

11 Z. Gao, T. Mori and R. Kondo, Biotechnol. Biofuels, 2012, 5, 28.

12 V. Pandey and M. Singh, Cell. Mol. Biol., 2014, 60, 29-34.

13 R. Bisaria, M. Madan and S. N. Mukhopadhyay, Biotechnol. Lett., 1983, 5, 811-812.

14 E. Jwanny, M. Rashad and H. M. Abdu, Appl. Biochem. Biotechnol., 1995, 50, 71-78.

15 Y.-C. Li, S.-Y. Wu, C.-Y. Chu and H.-C. Huang, Int. J. Hydrogen Energy, 2011, 36, 14245-14251.

16 C. H. Lay, I. Y. Sung, G. Kumar, C. Y. Chu, C. C. Chen and C. Y. Lin, Int. J. Hydrogen Energy, 2012, 37, 16473-16478.

17 T. Sheng, L. Gao, L. Zhao, W. Liu and A. Wang, RSC Adv., 2015, 5, 99781-99788.

18 L. J. Swatzell, M. J. Powell and J. Z. Kiss, Int. J. Plant Sci., 1996, 157, 53-62.

19 J. Lalak, A. Kasprzycka, D. Martyniak and J. Tys, Bioresour. Technol., 2016, 200, 194-200.

20 A. M. Mustafa, T. G. Poulsen and K. Sheng, Appl. Energy, 2016, 180, 661-671.

21 E. Wolin, M. J. Wolin and R. Wolfe, J. Biol. Chem., 1963, 238, 2882-2886.

22 R. Teeäär, R. Serimaa and T. Paakkarl, Polym. Bull., 1987, 17, 231-237.

23 a. Wang, L. Gao, R. Nanqi, X. Jifei, L. Chong, C. Guangli, Y. Hao, L. Wenzong, C. L. Hemme and H. Zhili, Appl. Environ. Microbiol., 2011, 77, 517-523.

24 A. Wang, N. Ren, Y. Shi and D.-J. Lee, Int. J. Hydrogen Energy, 2008, 33, 912-917.

25 M. M. Bradford, Anal. Biochem., 1976, 72, 248-254.

26 J. Wiegel, L. G. Ljungdahl and A. L. Demain, Crit. Rev. Biotechnol., 2008, 3, 39-108.

27 T. M. Wood and K. M. Bhat, Methods Enzymol., 1988, 87-112.

28 C. Wan and Y. Li, Biotechnol. Adv., 2012, 30, 1447.
29 E. Rouches, S. Zhou, J. P. Steyer and H. Carrere, Process Biochem., 2016, 51, 1784-1792.

30 R. Wang, T. You, G. Yang and F. Xu, ACS Sustainable Chem. Eng., 2017, 5(11), 10849-10857.

31 F. Ma, X. Huang, M. Ke, Q. Shi, Q. Chen, C. Shi, J. Zhang, X. Zhang and H. Yu, ACS Sustainable Chem. Eng., 2017, 5(10), 8884-8894.

32 S. Kuhar, L. M. Nair and R. C. Kuhad, Can. J. Microbiol., 2008, 54, 305.

33 R. Q. Song and X. Deng, J. For. Res., 2004, 15, 223-226.

34 N. C. Carpita and D. M. Gibeaut, Plant J., 1993, 3, 1-30.

35 L. Liu, J. S. Sun, M. Li, S. H. Wang, H. S. Pei and J. S. Zhang, Bioresour. Technol., 2009, 100, 5853-5858.

36 A. Alonso-Simón, P. García-Angulo, H. Mélida and A. Encina, Plant Signaling Behav., 2011, 6, 1104-1110.

37 M. D. Harrison, Z. Zhang, K. Shand, I. M. O'Hara, W. O. S. Doherty and J. L. Dale, Bioresour. Technol., 2013, 148, 105-113.

38 A. D. Moreno and L. Olsson, Pretreatment of Lignocellulosic Feedstocks, Springer International Publishing, 2017.

39 L. Ma, Y. Cui, R. Cai, X. Liu, C. Zhang and D. Xiao, Bioresour. Technol., 2015, 180, 1.

$40 \mathrm{H}$. Li and J. Xu, Bioresour. Technol., 2013, 127, 112-118.

41 M. Yamakawa, H. Abe and M. Okamoto, Nihon Chikusan Gakkaiho, 1992, 63, 129-133.

42 M. Sadler, Nutr. Bull., 2003, 28, 305-308.

43 J. Steiner, C. Socha and J. Eyzaguirre, World J. Microbiol. Biotechnol., 1994, 10, 280-284.

44 T. A. D. Nguyen, S. J. Han, J. P. Kim, S. K. Mi, K. O. You and J. S. Sang, Int. J. Hydrogen Energy, 2008, 33, 5161-5168.

45 Z. Zhi and W. Hui, Bioprocess Biosyst. Eng., 2014, 37, 1-12. 46 X. Y. Cheng and C. Z. Liu, Appl. Energy, 2012, 91, 1-6.

47 G. L. Cao, X. F. Xia, L. Zhao, Z. Y. Wang, X. Li and Q. Yang, Int. J. Hydrogen Energy, 2013, 38, 15653-15659.

48 H. Liu and G. Wang, Int. J. Hydrogen Energy, 2014, 39, 90129017. 